\title{
Vácuo no poder? Reflexões sobre a difusão do Primeiro Comando da Capital pelo Brasil
}

Vacuum in Power? Reflections on the Spread of the Primeiro Comando da Capital throughout Brazil

Vide au pouvoir? Réflexions sur la diffusion au Brésil du Primeiro Comando da Capital

\section{Thais Lemos Duarte}

\section{(2) OpenEdition}

\section{Journals}

Edição electrónica

URL: http://journals.openedition.org/rccs/10663

DOI: $10.4000 /$ rccs. 10663

ISSN: 2182-7435

\section{Editora}

Centro de Estudos Sociais da Universidade de Coimbra

Edição impressa

Data de publição: 1 setembro 2020

Paginação: 77-96

ISSN: 0254-1106

\section{Refêrencia eletrónica}

Thais Lemos Duarte, « Vácuo no poder? Reflexões sobre a difusão do Primeiro Comando da Capita pelo Brasil », Revista Crítica de Ciências Sociais [Online], 122 | 2020, posto online no dia 10 setembro 2020, consultado o 10 dezembro 2020. URL : http://journals.openedition.org/rccs/10663 ; DOI : https://doi.org/10.4000/rccs. 10663 


\section{THAIS LEMOS DUARTE}

\section{Vácuo no poder? Reflexões sobre a difusão do Primeiro Comando da Capital pelo Brasil}

O artigo analisa os pontos de vista de gestores da administração penitenciária federal sobre os fatores que ocasionaram a difusão do grupo criminoso paulista Primeiro Comando da Capital (PCC) pelo Brasil e os efeitos desse movimento nos sistemas prisionais estaduais. Muitos encaram o processo como fruto da "ausência" do Estado na formulação de políticas públicas e na garantia de direitos. A organização seria, portanto, consequência de vácuos de poder. Existem, no entanto, alguns pontos de dissonância quanto a este tipo de visão, os quais apontam que grupos nos moldes do PCC seriam fruto da própria ação do Estado. Neste sentido, as visões encontram-se em disputa, correspondendo a entendimentos distintos sobre a própria natureza estatal.

Palavras-chave: Brasil; crime organizado; intervenção do Estado; relações de poder; sistema prisional.

\section{Introdução}

Nascido e gerido a partir dos presídios de São Paulo, o Primeiro Comando da Capital (PCC), a maior organização criminosa brasileira, vive um momento de franca expansão e conta com representantes em 21 estados, inclusive no Paraná, além do Distrito Federal, Paraguai e Bolívia. ${ }^{1}$

Datado de 2012, o trecho da reportagem acima já mostrava relativa preocupação a um fenômeno amplamente discutido nos dias de hoje pela imprensa, pela sociedade civil e pelo poder público brasileiros: o processo de expansão da organização criminal Primeiro Comando da Capital (PCC) pelo país e por outras localidades da América Latina. Pelo relato,

${ }^{1}$ Agência O Globo (2012), "Relatório nacional aponta expansão do PCC pelo Brasil", Gazeta do Povo, 25 de novembro. Consultado a 10.08.2018, em https://www.gazetadopovo.com.br/vida-e-cidadania/ relatorio-nacional-aponta-expansao-do-pcc-pelo-brasil-2zabpa9yy7xqynx41daw050su. 
simultaneamente ao estabelecimento de sua hegemonia no território paulista, o grupo teria iniciado sua difusão em outros lugares, dissipando seus valores e estratégias de atuação a diferentes contextos.

A questão se projetou no debate público nos últimos tempos, sobretudo pelas violentas rebeliões que surgiram em unidades prisionais situadas nas regiões norte e nordeste do país. Presos do PCC teriam entrado em conflito com pessoas privadas de liberdade de outras organizações criminais, como o Comando Vermelho, ${ }^{2}$ gerando um cenário de grande "caos carcerário". ${ }^{3}$ Apenas no primeiro mês de 2017, mais de uma centena de presos foram assassinados em estabelecimentos de Roraima, Amazonas e do Rio Grande do Norte. ${ }^{4}$ Tornou-se evidente, pois, que o grupo paulista teria estendido seu domínio para diferentes áreas do país, muito além de São Paulo, transformando as dinâmicas e rotinas de distintos contextos carcerários.

A proposta do presente artigo é, a partir de dados obtidos via entrevistas semiestruturadas, discutir a percepção de gestores da administração penitenciária federal sobre o que motivou a difusão do PCC pelo Brasil e alguns efeitos desse movimento nos sistemas prisionais estaduais.

\section{Questões metodológicas}

Foram realizadas dez entrevistas semiestruturadas com gestores federais atuantes em órgãos voltados à construção da política penitenciária nacional, como o antigo Ministério da Justiça, o Departamento Penitenciário Federal (DEPEN), 5 o Conselho Nacional de Justiça (CNJ), assim como a extinta Secretaria Nacional de Segurança Pública. Todas as entrevistas

\footnotetext{
${ }^{2}$ Ao que tudo indica, a despeito de controvérsias e incertezas, o grupo foi instituído a partir da convivência entre presos comuns e os privados de liberdade enquadrados na Lei de Segurança Nacional, os ditos "políticos", durante o período da Ditadura Civil-Militar (1964-1985), em um cárcere situado na Ilha Grande, no Rio de Janeiro (Barbosa, 2005; Lourenço e Dias, 2015). Além das ambiguidades acerca do nascimento desta fação, é notável que numerosos acontecimentos tenham passado a atribuir-se ao grupo dentro e fora das prisões a partir da década de 1980.

${ }^{3}$ Em seu processo de expansão pelo Brasil, o PCC travou diversos embates com outras organizações criminosas. Neste cenário, ganha relevo o Comando Vermelho que, similarmente ao grupo paulista, também é identificado no debate público com pretensões de estender seu domínio por todo território nacional e por países latino-americanos. Até 2016, ambos os grupos eram aliados, mas a disputa pelo controle de rotas de drogas conduziu a rivalidades, gerando o contexto de rebeliões exposto na introdução desse artigo (Manso e Dias, 2018).

${ }^{4}$ Mazda, Aura (2017), "Rebeliões em série deixam 125 mortes e agravam crise no sistema", O Globo, 16 de janeiro. Consultado a 16.08.2018, em https://oglobo.globo.com/brasil/ rebelioes-em-serie-deixam-125-mortes-agravam-crise-no-sistema-20779376.

5 O DEPEN é o órgão atualmente ligado ao Ministério da Justiça e Segurança Pública, cuja função é acompanhar e controlar a aplicação da Lei de Execução Penal e as diretrizes da Política Penitenciária Nacional. É ainda o responsável pelo Sistema Penitenciário Federal.
} 
foram realizadas utilizando um software que permite a comunicação pela internet com conexão de voz e vídeo, como o Skype. Isso porque a pesquisa foi conduzida em um local distante do Distrito Federal, onde normalmente os órgãos de construção da política penitenciária nacional estão sediados.

Nestas entrevistas, o objetivo foi conversar com pessoas de diversos perfis políticos e profissionais. Alguns contavam com cargos estratégicos relativamente à questão prisional, a despeito de atualmente ocuparem outras posições. Adicionalmente, outros contavam com a pertença ao alto escalão governamental e outros ainda com uma atuação bastante própria, sendo fácil a sua identificação. Por conseguinte, a fim de evitar expor as suas posições, os trechos de entrevistas analisados neste artigo apenas mencionam os órgãos a que esses indivíduos pertencem ou pertenceram, não se especificando os seus cargos.

A pesquisa pretendia contatar gestores da administração prisional paulista, com vistas a compreender as concepções de tais atores sobre o modus operandi do PCC em São Paulo, comparando com a sua ação em outras partes do país. Tinha ainda como proposta analisar possíveis motivos para a difusão da organização pelo Brasil. Entretanto, apesar de inúmeras tentativas, verificou-se muita resistência para a marcação de entrevistas, não sendo possível efetuá-las. O estudo se referiu, então, apenas às noções de gestores federais, não abarcando informações de pessoas com atuação em áreas onde originalmente o PCC se originou e consolidou.

Após a apresentação geral do levantamento e do perfil dos dados utilizados nesse estudo, importa realizar algumas ponderações metodológicas. Em primeiro lugar, as análises conduzidas no texto partem de uma perspectiva distinta da normalmente utilizada em estudos sobre o PCC. Em geral, pesquisas e debates acadêmicos realizados sobre o grupo se pautam pelo método etnográfico em áreas dominadas pela organização criminal e se baseiam em entrevistas realizadas com presos que dizem pertencer ao PCC. Telles (2013) afirma que, no decorrer dos últimos anos, os estudos relativos à organização e a outros temas ligados a ilegalismos de cenário urbano se multiplicaram, compondo o que se poderia chamar de uma experiência etnográfica. Deste modo, praticamente não existem análises com foco nas narrativas de gestores públicos sobre as dinâmicas de atuação do PCC. Recomenda-se, assim, particular atenção quanto a possíveis incongruências entre o encontrado nesse artigo e o debatido em pesquisas anteriores.

Em segundo lugar, o estudo da narrativa de gestores sobre a expansão do PCC introduz um novo desafio metodológico na pesquisa. Este tipo de abordagem pode oferecer uma noção bastante parcial sobre o objeto 
de estudo, pois abarca percepções mais institucionais sobre a organização. Em decorrência disso, tais noções costumam estar entranhadas de estereótipos, muitos dos quais estigmatizantes quanto a certas populações, normalmente as mais pobres (Ramos e Musumeci, 2005). Uma maneira de reverter esse problema, ainda que não totalmente eficaz, é apontar sempre que possível as limitações das informações observadas. Outra forma de solucionar este desafio metodológico é ponderar determinadas considerações, comparando os dados obtidos com análises já realizadas em outros estudos.

Por certo, os dados utilizados envolvem interesses de um grupo de atores específico, pois supõe-se que os gestores públicos busquem valorizar concepções que ensejam suas atividades de trabalho. Caso estivessem em análise, por exemplo, as narrativas de presos vinculados ao PCC ou de seus familiares, surgiriam outros interesses em jogo, possivelmente voltados à denúncia de condições carcerárias e ao reforço positivo da organização criminal. Uma maneira de trabalhar este possível viés seria não tomar como verdadeiros os relatos produzidos pelos distintos informantes, muitos dos quais, inclusive, se encontram em disputa. Isto é, os dados trabalhados neste texto dizem muito mais sobre o modo como os gestores compreendem o fenômeno em estudo e sobre as características do aparelho público que compõem. Não esclarecem necessariamente sobre as "efetivas" características do PCC e sobre os "verdadeiros" aspectos da expansão do grupo pelo Brasil. Ainda que à primeira vista possa parecer algo simplória, essa estratégia analítica permite certo distanciamento do objeto de pesquisa, possibilitando maior refinamento analítico e sociológico.

Em suma, os dados utilizados neste artigo são importantes para a análise do objeto em questão, mas, como toda e qualquer fonte, possuem limitações que devem ser explicitadas e discutidas. O problema não reside na sua utilização, mas na ausência de crítica sobre a forma de os utilizar (Dias, 2011).

\section{O PCC nas margens do Estado}

A constituição do PCC pode ser dividida em três fases, cada qual com diferentes ordenamentos. O grupo foi fundado em 1993, durante uma rebelião no Centro de Reabilitação Penitenciária, anexo à Casa de Custódia e Tratamento de Taubaté, em São Paulo. Segundo Dias (2011), de 1993 até 2001 ocorreu uma violenta expansão do grupo dentro do sistema prisional paulista, sendo estabelecidos padrões comportamentais com uma importância simbólica entre os presos, como, por exemplo, o fim dos estupros. Esta primeira fase pode caracterizar-se por um crescimento constante da violência e por eventos de rupturas da ordem nas prisões. 
O intervalo entre 2001 e 2006 correspondeu a um segundo momento de formação do grupo (Dias, 2011). No primeiro ano deste período ocorreu uma rebelião de grandes dimensões comandada pelo PCC. Por um lado, ensejou um aumento da repressão pelos órgãos de controle do Estado, levando à instauração do Regime Disciplinar Diferenciado (RDD). ${ }^{6}$ Por outro, uma rebelião de tal dimensão conferiu prestígio e respeito aos membros do PCC, fortalecendo e impulsionando a sua disseminação pelo sistema prisional, bem como pelas periferias de São Paulo.

Esse quadro foi crucial para a entrada do PCC em sua terceira fase (ibidem). O período foi inaugurado por grandes rebeliões em diversas prisões paulistas, ocorridas ao longo de 2006, especialmente em maio desse ano. Além da ação do PCC nos cárceres, alguns postos, viaturas, delegacias de polícia e diversos outros tipos de prédios públicos foram objetos de ataques armados, nos quais os principais alvos consistiram em policiais e agentes penitenciários. A polícia, então, reagiu. As folgas e férias de seus agentes foram canceladas, sendo todo o efetivo posto nas ruas. Entre 12 e 21 de maio de 2006, na chamada "semana sangrenta", centenas de pessoas foram mortas. A violência excessiva das ações policiais e a explícita atividade de grupos de extermínio causaram grande preocupação (Cano e Alvadia, 2008).

De acordo com Adorno e Dias (2016), os atentados de 2006 conformaram as relações de poder no sistema prisional, cuja base seria a acomodação entre a massa carcerária - sob a liderança do PCC - e a administração penitenciária. O Estado revelara-se incapaz de conter possíveis motins comandados pelo grupo. Apenas o PCC poderia evitar tais eventos, "disciplinando" os presos, conforme seus preceitos e valores. Em outras palavras, a hegemonia do PCC seria a condição necessária para a manutenção da política penal principal executada no Brasil, o encarceramento em massa, ${ }^{7}$ ao passo que este mesmo fenômeno, acrescido das péssimas condições de privação de liberdade, se constituiria como elemento

\footnotetext{
${ }^{6} \mathrm{O}$ RDD é aplicado a presos provisórios e condenados, os quais cometeram crimes dolosos durante a privação de liberdade ou ocasionaram "subversão da ordem ou disciplina" carcerária. Apresenta as seguintes características: aplicação máxima de 360 dias; recolhimento do preso em cela individual; visitas semanais de apenas duas pessoas, com duração de duas horas; banhos de sol com intervalo de duas horas. Para maiores detalhes, ver artigo 52 da Lei de Execução Penal, n. ${ }^{\circ}$ 7210/1984 de 11 de julho, Brasília, Presidência da República.

7 Conforme Garland (2008), a estratégia de encarceramento em massa vem sendo aprofundada em diversos países, principalmente através da política contra as drogas. Essa tendência também surge no Brasil, de forma que, em junho de 2016, a população prisional brasileira ultrapassou pela primeira vez a marca das 700 mil pessoas privadas de liberdade, o que representa um aumento da ordem de $707 \%$ em relação ao total registrado no início da década de 1990 (DEPEN, 2017).
} 
essencial ao fortalecimento do PCC (Adorno e Dias, 2016). Um elemento reforçaria o outro. ${ }^{8}$

Desenvolveu-se, pois, uma simbiose entre ambos os atores, cujo efeito prático foi o estabelecimento de uma espécie de calmaria no sistema prisional paulista após 2006. Praticamente desapareceu a expressão simbólica do poder presente durante o processo de expansão e consolidação do PCC pelas prisões e, ainda, nas periferias das cidades paulistas, com assassinatos cruéis e o seu domínio fulminante (ibidem). Até mesmo porque, nesta etapa, o grupo consagrou a sua hegemonia, se consolidando como uma nova figura social dentro e fora das prisões de São Paulo. Assim, surgiram formas mais racionais de atuação, com execuções planejadas, circunscritas a questões específicas. Em consequência, os índices de homicídio do estado de São Paulo se reduziram a partir da consecução dos "debates" do PCC nas periferias, comumente identificados pela imprensa como "tribunais do crime" (Dias, 2011; Feltran, 2010). Ou seja, o grupo monopolizou o emprego da violência legítima no "mundo do crime" (Ramalho, 1983), alcançando a prerrogativa de controlar e regular as atividades ilícitas que compõem o núcleo da economia criminal paulista.

Essa dita "pacificação" espelha em algum nível as relações de força e os jogos de poder inscritos na produção da ordem (Telles, 2013). Empiricamente, é algo que se mostra a todo o momento nas evidências das dinâmicas processadas nos instáveis acordos e acomodações entre grupos criminosos e forças policiais em torno dos negócios ilícitos. Não poucas vezes, tais eventos desandam em disputas abertas, acionando ciclos recorrentes de mortes violentas e extermínios. Além de levar a este tipo de desfecho, ainda que não resultem em mortes tais eventos podem confluir para a linha tênue entre o legalismo/ilegalismo, banhada em negociações de natureza duvidosa, muito distante da rígida ordem que em teoria perfaria o aparelho estatal.

\footnotetext{
${ }^{8}$ A política de encarceramento em massa não apenas estimularia a formação de grupos organizados como o PCC, como teria impactos em outros atores ligados ao sistema prisional, como os familiares de presos (Sinhoretto et al., 2013). De igual maneira, afetariam as dinâmicas carcerárias existentes, transformando-as. Nos últimos anos, por exemplo, houve um aumento exponencial de presos que dizem pertencer à religião evangélica, em detrimento de outras religiões como a católica. Conforme Dias (2007), o grupo evangélico oferece à pessoa privada de liberdade a possibilidade de se sentir parte integrante de uma comunidade, de estabelecer laços sociais que a vincule novamente à sociedade e que dê sentido à sua pertença social. Os evangélicos são facilmente distinguíveis dentro da cadeia, seja por sua aparência, seja pelo seu "retraimento" e pelo modo de falar, baixo e subserviente, sem uso de gírias, traço característico da população prisional. Procuram se separar dos demais para demonstrar a todos - funcionários, presos, pesquisador, família, etc. - a mudança radical que aconteceu em sua vida, de "saída" do mundo do crime.
} 
De fato, na concepção clássica weberiana (Weber, 1982), uma organização política com operações contínuas é chamada de Estado na medida em que seu aparato administrativo mantenha para si, com êxito, o monopólio do uso legítimo da força na produção da ordem. Seria considerada ilegítima qualquer forma de violência que, por um lado, pareça imitar a violência legítima do Estado e, por outro, desafie o controle estatal. Como compreender, então, as produções da ordem/desordem, dos legalismos/ilegalismos, em que há participação direta de agentes públicos?

Este questionamento pode ser respondido através do debate sobre as margens estatais. Das e Poole (2008) apontam que tais margens podem ser interpretadas, dentre outros modos, como espaços entre os corpos, a lei e a disciplina. Esses lugares não são meramente territoriais, produzindo também locais em que a norma e outras dinâmicas estatais são colonizadas através de formas de regulação emanadas das necessidades das populações, com vistas a assegurar suas demandas políticas e econômicas. O Estado não estaria ausente em suas bordas. Ao contrário, as margens são espaços em que o aparelho estatal se conforma continuamente, redefinindo suas normas através da violência, autoridade e corrupção. Ao invés de serem produzidas por uma quebra em sua regulação, as margens se formam pela pluralidade das autoridades regulatórias existentes e, assim, conformam as características do aparato de controle. Essas ditas margens são supostos necessários ao funcionamento do Estado (ibidem).

Por outro lado, paira no senso comum a ideia de que o dito crime organizado concorreria com o Estado. Nesta ótica, as organizações criminais, como o PCC, surgem como produto de uma "ausência" estatal no processo de formulação de políticas públicas e na garantia de direitos, dominando territórios que formalmente deveriam ser "geridos" pelo Estado - sejam prisões, sejam áreas periféricas de grandes cidades. Tudo passa a ser explicado através de um paralelismo e/ou de um acoplamento indevido dos grupos ao aparelho estatal (Rafael, 2001).

As dinâmicas do tráfico se transformam, assim, em uma espécie de contraponto às ações do Estado. As organizações que gerenciam esse tipo de atividade criminal não só o imitariam, como também desenvolveriam uma espécie de concorrência. Não à toa, "poder paralelo" se tornou expressão comum como referência ao tráfico de drogas, deixando evidente que há um reconhecimento de que as ações de grupos criminosos se concretizam na medida em que seja possível traçar analogias entre a atividade ilícita e os modos de funcionamento estatal (Rafael, 2001). No entanto, reforçar esse ponto de vista é garantir consistência ao Estado, na forma de afirmação de sua total soberania. O Estado parece ser nessa perspectiva um todo indiviso, 
sem atritos ou dissonâncias em seu interior, se aproximando muito da já citada concepção clássica weberiana (Weber, 1982) e distanciando-se da discussão sobre margens. ${ }^{?}$

Essa mesma narrativa do senso comum também repercute sobre as dinâmicas dos grupos ligados ao tráfico de drogas. Ou estes são percebidos como algo extremamente difuso, fluido, movido por interesses imediatos e sem conexões; ou são analisados como uma estrutura sólida, piramidal, com movimentos e abalos, mas, sobretudo, com peso (Rafael, 2001). As duas visões ocultam uma dimensão segmentar, cujos efeitos são ontologizar o tráfico de drogas e transformar seus "movimentos" em algo meramente substantivo. Rafael (ibidem) aponta que essa linha de análise congela todo o devir em proveito da constituição do "ser" da organização criminal.

De fato, conforme Biondi (2014), o PCC forma "movimentos", concebidos como um sujeito coletivo de contornos indefinidos. Não há restrições quanto ao que pode compô-los, como, por exemplo, pessoas, situações, relações afetivas, quebradas, etc. Contudo, os arranjos são sempre momentâneos. Se os movimentos ganham vida a partir de diferentes elementos, logo outros novos auferem espaço, substituindo os anteriores. Desse modo, o PCC não se limita à trajetória das pessoas, mesmo à dos "irmãos", bem como não se confina a redutos. Os movimentos se cruzam, convivem, disputam, acoplam-se uns aos outros. Em outras palavras, há no PCC constantes jogos de forças e tensionamentos decorrentes dos esforços dos "malandros" em imprimir rumos que lhes pareçam mais favoráveis (ibidem).

Tendo como lema "paz entre os ladrões e guerra contra a polícia", o PCC é caracterizado por uma heteromorfia e uma heterogeneidade (ibidem). Ou seja, uma ausência de delimitações temporais, de contornos espaciais, de limite quanto ao que pode compô-lo; fugidio a qualquer tentativa de totalização. Em contrapartida, o PCC não é formado por uma série de acontecimentos desconexos ou por uma totalidade repleta de contradições, lacunas ou inconsistências. Resulta, sim, de uma maneira singular de conceber o mundo (ibidem).

Qual seria a perspectiva de gestores públicos federais sobre o tema em questão? Como analisam tais atores a expansão do PCC pelo Brasil? Em que medida as narrativas proferidas por esse grupo de pessoas se aproximam ou se distanciam da literatura existente sobre o grupo paulista? As seções seguintes buscarão responder a estas questões.

\footnotetext{
${ }_{9}$ Parte deste enquadramento teórico foi usado em Duarte (2019: 10-11).
} 


\section{Perspectivas sobre a expansão do PCC pelo Brasil}

Apesar de as ações do PCC pelo Brasil estarem na pauta das discussões sobre política penitenciária nacional, não há um ponto de vista muito consistente sobre o tema entre os gestores. ${ }^{10} \mathrm{~A}$ maioria parece mistificar a organização, dotando-a de grande força econômica, alta capacidade organizativa, forte capilaridade pelo Brasil e por países da América Latina, assim como de grande inserção na seara política. Essa interpretação em alguma medida faz menção ao disposto por Rafael (2001) a respeito de análises que reforçam as organizações criminais como estruturas sólidas, com peso.

Por outro lado, há aqueles que pontuam a necessidade de um olhar mais neutro sobre o PCC, evitando tanto a sua "demonização" quanto a sua "glamourização". Existem, pois, incertezas em torno do assunto, já que muito do que se conhece se baseia em informações transmitidas "boca a boca". Por outro lado, é curioso o fato de, a despeito de não haver consensos sobre o tema, a perspectiva de tais atores fundamentar e produzir diretrizes relativas à política penitenciária nacional, com impacto nos sistemas prisionais e nas políticas de segurança pública locais.

Quando a gente entra nessa área de segurança pública, isso vira um nó sem fim. Então, a gente tem muito pouca coisa de acúmulo útil no sentido de que: "Olha o gestor chega, então, e vai assumir uma determinada distribuição, determinado posto, ele vai ter acesso a uma informação mastigada?". Não! É um pouco boca a boca que a gente sempre fica um pouco em dúvida se estão aumentando a história para valorizar, se tem alguma coisa por trás daquela narrativa ou se é uma descrição do que a pessoa conseguiu acessar sobre aquela história mesmo. (Entrevista com gestor $\mathrm{C}-\mathrm{CNJ}$ )

Conforme os gestores, assim como outras organizações criminais originárias dos cárceres, o PCC teria surgido da "necessidade humana" de se agregar. Nas prisões, o grupo paulista seria uma espécie de "irmandade", com a tarefa de dotar os indivíduos de algum nível de autoridade frente à administração prisional, em busca de garantias por determinados direitos. De acordo com os relatos abaixo, entre outros aspectos, o PCC ajudaria a proporcionar insumos materiais aos presos, mediaria rivalidades no cárcere e definiria códigos de conduta. Tornaria também a vida na prisão menos

\footnotetext{
${ }^{10}$ No site do DEPEN, no campo sobre "perguntas frequentes", indica-se o total de presos que supostamente pertenceriam ao PCC e a outras organizações criminais. Não fica clara a abrangência do dado - se corresponde a todo o Brasil ou apenas a presídios geridos pelo DEPEN -, mas a forma como a informação está exposta na internet denota o quanto o órgão é demandado sobre o assunto e, por sua vez, a preocupação em se fornecer algum tipo de resposta à questão. Ver http://depen.gov.br/DEPEN/servicos/sobre/perguntas-frequentes (consultado a 17.08.2018).
} 
tensionada por possibilitar uma espécie de pacificação entre os reclusos através da imposição de medidas moralizantes, como a proibição do uso de certas drogas (por exemplo, o crack).

A partir do momento que esses presos começam a se sentir pertencentes a uma sociedade, porque eles têm uma sociedade de irmandade, isso vai dando o empoderamento individual. Porque o indivíduo para viver em uma sociedade ele tem que sentir, você sabe mais do que eu disso até... Ele tem que ter uma questão de... se sentir pertencente a determinado grupo. (Entrevista com gestor D - DEPEN)

O PCC dá conta do colchão, dá conta das briguinhas, tem as regras, entre eles. Não pode matar, não pode isso, não pode aquilo, não pode usar droga... Não pode usar droga não, não pode usar crack. Eles têm as regras deles que são rígidas, muito mais do que do próprio Estado. (Entrevista com gestor B - DEPEN)

Outros gestores chamam a atenção sobre o fato de o PCC apresentar uma estrutura de "empresa", sendo uma "máquina de fazer dinheiro", cujo objetivo final seria o lucro "a qualquer custo". Realiza-se, então, uma leitura quase moral sobre as ações do grupo. A vida das pessoas, os efeitos do comércio de drogas e as consequências da venda de armas à sociedade ficariam em segundo plano, pois o importante seria a ampliação dos seus negócios.

Portanto, ao que tudo indica, na visão dos gestores o PCC assume uma feição idiossincrática. Não obstante, conforme Manso e Dias (2018), o PCC comportaria características de empresa, igreja e irmandade, sendo oblíquo fechar um olhar único sobre o grupo. Um retrato da organização está diretamente relacionado ao prisma utilizado para mirá-la. Caso for desconsiderado esse cuidado metodológico e analítico, incorre-se no risco de não se abarcar todas as complexidades e movimentos que perfazem o grupo, tal qual disposto por Biondi (2014).

Como dito, a opinião de gestores públicos em torno de temas sobre os quais se debruçam em suas rotinas de trabalho poderia ser distorcida, já que tais atores poderiam buscar reforçar ações e políticas que comumente executam. Neste sentido, seria presumível que articulassem um repertório positivo tanto sobre as atividades que desenvolvem quanto a respeito dos órgãos públicos em que trabalham ou apresentam algum nível de interlocução. No entanto, distante dessa hipótese, boa parte das pessoas contatadas trouxe como pano de fundo de suas análises a ideia de um Estado "falido", "fraco", "incapaz" de disciplinar a "massa carcerária" e "garantir direitos" aos presos, sendo que elas próprias constituem este 
dito ente. Parece ser não só uma forma de desresponsabilização sobre o contexto prisional existente, mas também um reconhecimento sobre a ineficácia das políticas penais comumente executadas no país, ainda que tais gestores estejam à frente de processos de criação de políticas e diretrizes penitenciárias. ${ }^{11}$ A crítica corre no sentido de o Estado "achar bom" o PCC ter influência nas prisões, pois deixaria de ter de lidar diretamente com determinadas rotinas carcerárias, geradoras de desgaste e tensionamento aos agentes prisionais.

Então para o gestor... e isso é muito triste, sabe, porque às vezes, silenciosamente, ou às vezes nem tanto, porque o depoimento desse diretor já não foi tão silencioso. O Estado está achando bom que tenham essas organizações dentro dos presídios. (Entrevista com gestor B - DEPEN)

Por certo, o próprio perfil preponderante nos dias de hoje desses agentes é analisado em tom de censura. Tais profissionais não teriam experiência para custodiar as pessoas privadas de liberdade, reforçando, assim, um "Estado fraco".

Ele [o Estado] não criou uma estrutura de pessoal tão alinhada quanto era antes, então quem for [a]os concursos públicos, os profissionais agentes prisionais todos que foram contratados para o interior no primeiro momento, era um grupo de pessoas muito mais frágeis, muito menos experientes, e que não conseguiu fazer frente a essa massa tão sedimentada de angústias e reinvindicações e que se tornou esse grupo PCC [...]. (Entrevista com ex-gestor A - DEPEN)

Não obstante, menções a "sociedades paralelas", "vácuos de poder", bem como análises dicotômicas sobre "ausência" e "presença" foram pontos comuns nas narrativas dos gestores para explicar o surgimento e fortalecimento do PCC em São Paulo. Mobilizando uma perspectiva sobre o Estado como uma instância máxima de gerência administrativa e burocrática, o PCC teria ganhado corpo em confronto às estruturas organizacionais. Ou seja, conforme as narrativas a seguir, o grupo teria se feito "presente" pela "ausência" de políticas prisionais e de segurança pública em âmbito nacional.

\footnotetext{
${ }^{11}$ Os gestores federais não costumam ter incidência direta nos sistemas prisionais estaduais, tendo apenas a atribuição de dispor orientações às administrações penitenciárias das distintas unidades da federação. Alguns dos atores contatados somente regulam e atuam diretamente sobre o sistema penitenciário federal, o qual está subordinado ao DEPEN.
} 
Tudo tem uma explicação e acaba criando uma sociedade paralela em todos esses ambientes que o Estado não se faz presente e a gente sabe que o ambiente carcerário é um ambiente totalmente propício para essa ausência estatal. As facções criminosas passaram a ser o Estado dentro da cadeia, mas quem dá mais sentido para o outro acaba sendo o PCC mesmo. (Entrevista com gestor E - DEPEN)

Então, acaba criando uma ordem na sociedade fora também, onde eles estão presentes, que são sempre nessas sociedades de uma ausência de Estado. [...] Então, eles vão preenchendo lacunas nessas ausências estatais o tempo inteiro e eles vão tendo cada vez mais respeito, mais pessoas, mais adeptos e tudo mais. (Entrevista com gestor B - DEPEN)

Usadas não só para justificar o crescimento e hegemonia do PCC em São Paulo, a "fraqueza" e "ausência" do Estado se tornaram eixos explicativos centrais para se discutir a difusão da organização pelo Brasil. Segundo os entrevistados, os problemas carcerários existentes no território paulista são comuns ou até mais agudos em outras unidades da federação. Entre outras dinâmicas, superlotação, carência de insumos materiais, ausência de vagas de trabalho, falta de acesso ao estudo e práticas de tortura marcam os cenários prisionais de basicamente todos os estados. De acordo com os gestores, o PCC teria planos desde momentos mais remotos de se expandir para localidades diferentes de São Paulo e teria "aproveitado" o contexto de completa "ausência" do Estado em todo o país para agir de tal modo.

Os fatores de expansão são justamente... Então, porque o PCC... a gente sabe como começou o PCC, não é? A ausência do Estado. [...] Pela ausência do Estado, [que] não se organiza, [quando] o Estado não dá condição, alguma organização dá. (Entrevista com gestor B - DEPEN)

Ele [o PCC] já tem essa questão de expansão, ele sempre teve. Eu tive oportunidade de ver um manuscrito dele mesmo, ele falando de dominação de mundo em 2011. Eles fazem uma cartilha já falando que eles vão dominar todas as partes, que o Brasil todo vai conhecer [...]. Uma questão mundial de expansão, já é uma ideia da própria liderança. Então ele já tinha isso como uma ideia de expansão. (Entrevista com gestor D - DEPEN)

Nas perspectivas em questão, um possível contraponto aos sistemas prisionais estaduais seriam os estabelecimentos federais. À primeira vista, o fato de indivíduos ditos "periculosos" pelo sistema de justiça criminal cumprirem pena em regime mais rígido ensejaria um maior controle na aplicação da 
pena privativa de liberdade e, deste modo, seriam menores as chances de fortalecimento de organizações criminais. Isto é, um "sistema duro", como exposto abaixo, garantiria uma privação de liberdade mais eficiente. ${ }^{12}$

Olha, ele [o sistema penitenciário federal] foi desenvolvido no governo Lula e fundamentalmente eram problemas atinentes a não deixar presos de alta periculosidade nos estabelecimentos estaduais. Então, criaram-se a partir daí os presídios de segurança máxima federal que tem um padrão de eficiência muito grande, mas se destina a receber exclusivamente os presos de alta periculosidade. Ou seja, ele tem um sistema duro. (Entrevista com ex-gestor C - Ministério da Justiça)

Por outro lado, esse mesmo sistema penitenciário federal é visto como um dos fatores de expansão do PCC para os distintos territórios brasileiros. A despeito de terem se desenvolvido sob um viés oposto, as prisões federais são analisadas como estruturas organizacionais "fracas". Ao invés de ultrapassar a dicotomia entre "fraqueza" e "força", bem como "ausência" e "presença", questionando modelos penais voltados ao endurecimento da pena, a posição preponderante entre os gestores é de reforço da linha analítica com base em um Estado "duro", detentor do monopólio da violência legítima.

Culpa-se muito o próprio sistema penitenciário federal que é nosso. O PCC se expandiu depois da criação das penitenciárias federais porque se pegou líderes [sic] e foi colocado no sistema penitenciário federal, lá encontraram outros líderes e se expandiu. Vamos jogar uma parcela disso. (Entrevista com gestora B - DEPEN)

De fato, algumas narrativas indicam que o PCC teria começado a sua difusão antes da inauguração do sistema penitenciário federal, ocorrida em 2006. Conforme um ex-gestor da Secretaria Nacional de Segurança Pública, o grupo teria começado a estender seus braços para fora dos limites territoriais paulistas ainda em 1998, momento que a literatura sobre o tema indica ser o início da fase de dispersão do grupo às prisões de São Paulo (Dias, 2011).

Para evitar o fortalecimento da organização, o poder público paulista resolveu dissolver lideranças de presos do PCC, transferindo-as para o Paraná.

\footnotetext{
${ }_{12}$ O primeiro presídio federal surgiu em 2006, chamado de Penitenciária Federal de Catanduvas no Paraná. Atualmente estão em funcionamento cinco presídios federais no país: além de Catanduvas, há a Penitenciária Federal de Campo Grande, a Penitenciária Federal de Porto Velho, a Penitenciária Federal de Mossoró e a Penitenciária Federal de Brasília. Para mais informações, ver notícia no site da DEPEN, "Conheça o Sistema Penitenciário Federal", de 3 de dezembro de 2019. Consultado a 01.09.2020, em https://www.novo.justica.gov.br/news/conheca-o-sistema-penitenciario-federal.
} 
Essa medida foi realizada com muita discrição. Até mesmo porque a privação de liberdade foi designada para ser cumprida em um estado e, portanto, sob o controle de um sistema de justiça criminal diferente de onde um grupo de presos recebeu sua condenação. Segundo os gestores, esse episódio foi apenas o início de um movimento aprofundado ao longo dos últimos anos. Não à toa, como dito em seção anterior, uma das respostas do Estado aos atentados em 2006 em São Paulo foi a transferência de lideranças do PCC para o RDD. Por sua vez, após atentados isolados no estado em 2012, sobre os quais até aos dias de hoje não há uma definição clara sobre sua autoria, o governo paulista transferiu lideranças do PCC para estabelecimentos penitenciários federais (Silvestre, 2016). Inclusive, em momentos em que a ação da organização não era tão visibilizada na imprensa, tampouco era sentida por determinados grupos sociais, o Estado continuava a enviar sistematicamente presos a cárceres federais para "isolamento" (Duarte e Araújo, 2020).

Em outras palavras, instaurou-se uma espécie de política de castigo de lideranças da organização criminosa, cujo efeito foi aprofundar os ilegalismos relacionados ao cárcere e, em consequência, a propagação do grupo pelo país. Os presos de São Paulo teriam começado a se comunicar com pessoas privadas de liberdade do Acre, do Rio Grande do Norte, do Mato Grosso do Sul, entre tantos outros locais. Além da transferência para prisões situadas em estados diferentes de São Paulo, a organização teria começado a enviar seus membros a outros territórios. Conforme os gestores, seriam abertas espécies de "franquias", a partir do "batismo" de novos integrantes, isto é, cerimônias em que o indivíduo adere às normas do grupo e se torna membro do PCC. Essas pessoas recém-filiadas ajudariam a disseminar valores junto de outros futuros integrantes.

Os entrevistados apontaram que a mesma lógica organizacional estruturada em São Paulo seria reproduzida nos estados para onde o PCC teria se expandido. Diferente de outros grupos como o Comando Vermelho, os quais pulverizariam suas ações interagindo com outras organizações locais, o PCC visaria estresir valores desenvolvidos no território paulista a outras áreas. Para os gestores, as alianças com outros grupos são sempre momentâneas, voltadas a um interesse pontual para, em seguida, serem desatadas. Sob esta perspectiva, as lideranças do PCC gostariam que os integrantes "vestissem a camisa" da organização. Não interessa a produção de novas práticas e o desenvolvimento de novos valores.

O PCC ele ata e desata [alianças]. Ele ata só em um momento muito particular ali, mas ele não tem o interesse de ficar com alianças formadas. Ele tem interesse 
pontualmente se for para combater o Comando Vermelho, que é o principal rival dele. Aí ele tem interesse, se for para isso ele tem interesse. Mas o que ele faz ao longo do tempo? Ele vai dando um jeito de dar um chega para lá naquela aliança que ele fez e faz com que seus membros passem a ser PCC e aquela parceria seja desfeita e os melhores ele pega para ele. E aqueles idiotas ele não quer também, eles vão selecionando. Eles não querem ter 1500 idiotas, eles preferem ter 1200, mas melhores. Para você ver como eles pensam igual [a] uma empresa, tudo é pensado como uma empresa. Então eles não querem saber de muita aliança, eles querem saber de novos filiados, que vão realmente vestir a camiseta. (Entrevista com gestor B - DEPEN)

A incorporação de novos membros ao grupo, com a adesão integral aos seus valores, é analisada como fundamental à sustentabilidade do PCC em outros estados. Um gestor apontou para a preocupação do grupo em identificar lideranças "parceiras" em territórios distintos a São Paulo, evitando "vácuos de governabilidade". Até mesmo porque tais lacunas poderiam permitir a "entrada" do Estado nas dinâmicas prisionais ou garantir o crescimento de outra organização criminal, o que, em ambas as situações, impediria a consolidação do PCC em determinada localidade.

O interessante é que, apesar de boa parte das narrativas dos gestores entrevistados deliberadamente se pautar pela "fraqueza" e "ausência" do Estado, há traços em seus discursos que destoam desse eixo analítico, se aproximando do debate sobre a produção de ilegalismos nas margens (Telles, 2013; Das e Poole, 2008). No trecho abaixo, o entrevistado chama a atenção para três estados onde a organização teria estendido com força seu domínio e, por sua vez, ocasionado maior impacto nas rebeliões citadas na parte introdutória do artigo - Roraima, Amazonas e Rio Grande do Norte. Ao invés de usar uma grande soma financeira repassada pelo governo federal há alguns anos ao aprimoramento do seu sistema penitenciário, o governo de Roraima teria desviado a maior parte da verba. A pessoa responsável pelo fato morreu de modo misterioso, não tendo se avançado efetivamente nas investigações.

O fato é que a gente tinha que também levantar um olhar um pouquinho para cima e mostrar que tem um traço característico para os três estados. São três estados que estão vivenciando problemas crônicos no sistema prisional, cujos governantes, dirigentes do poder executivo estadual, governador, governadores que passaram por Roraima, pelo Amazonas, muito pouco fizeram seja para executar recurso federal, seja pra aportar algum recurso local. Então, se chegaram a situação que você tem no Rio Grande do Norte, no sistema prisional do Rio Grande do Norte e o mesmo em Roraima [...]. Mas acho que é um misto ali de coisas para reunir 
o que aconteceu, acho que é uma possível sim flexão entre grupos distintos, com uma possível facilitação criminosa, uma crônica incompetência, desinteresse, talvez criminoso. Também talvez configure p[a]ra unidade administrativa. Aliás, o estado de Roraima tem indicativos claros de sumiço de recursos que foi repassado agora em dezembro. A história do secretário que usou o cartão para gastar dois milhões e morreu em uma pescaria também são umas histórias escabrosas. Mas eu acho que é um conjunto de fatores que a gente teria que aprofundar caso a caso, mas como grande traço característico uma negligência crônica e continuável dos governos estaduais. Os governos não têm o mínimo de organização, o mínimo de controle, o mínimo de recursos para que aquelas unidades estivessem funcionando. (Entrevista gestor $\mathrm{C}-\mathrm{CNJ}$ )

Em outras palavras, ainda que de modo indireto, há entre alguns gestores um grau de entendimento de que o Estado exerceria práticas situadas na linha tênue entre o legalismo e ilegalismo. Pondera-se em alguma medida que um dos efeitos de tais ações seria a formação de processos contínuos de modelagem e remodelagem de realidades locais, fomentando o fortalecimento e a difusão de organizações criminais para diferentes territórios, como o PCC.

\section{Considerações finais}

$\mathrm{O}$ artigo visou a discutir o ponto de vista de gestores da administração penitenciária federal sobre possíveis motivações à difusão do PCC pelo Brasil e alguns efeitos desse processo aos sistemas prisionais estaduais. Prepondera o discurso de que a propagação do grupo paulista seria fruto da "ausência" do Estado na formulação de políticas públicas e na garantia de direitos das pessoas privadas de liberdade. Com vistas a ocupar "vácuos" de poder, o PCC teria se consolidado não só como grupo hegemônico em São Paulo, como também teria expandido seus braços a distintos territórios nacionais. Atando e desfazendo alianças com outras organizações criminais, assim como "batizando" novos membros, o PCC estaria em movimento crescente de alastramento de seus valores a variadas localidades, gerando impactos significativos em distintos contextos carcerários, como as rebeliões que ocasionaram a morte de mais de uma centena de presos no primeiro mês de 2017.

No geral, torna-se possível afirmar que as narrativas dos gestores se aproximam em boa medida de uma perspectiva quase clássica sobre o Estado. Ao apontar que, a depender de suas ações, este ente pode formar lacunas em sua esfera de poder, utiliza-se como ponto de partida a ideia de que haja uma instância em cujas mãos se monopoliza a violência legítima. 
Por outro lado, mesmo que sustentem em peso tal noção, certos informantes apontam para a ineficácia das políticas penais comumente executadas no país, pautadas sobretudo pelo aumento contínuo nos níveis de encarceramento. Mesmo que tangencialmente, certos gestores compreendem que muitas práticas estatais se situam na linha tênue entre o legal e ilegal, se desvencilhando por vezes de explicações dicotômicas ligadas à "ausência" e à "presença”. Pondera-se que um dos efeitos dessas ações estatais seria a formação de processos contínuos de modelagem e remodelagem de realidades locais, estimulando, entre outros aspectos, a expansão do PCC pelo Brasil. Esta narrativa se aproxima em muito da perspectiva sobre a produção da criminalidade nas margens estatais, proposto por Telles (2013) e Das e Poole (2008).

As concepções sobre o objeto analisado neste artigo parecem estar em disputa, ora imperando a ideia - que certamente apresenta maior peso - de o PCC nascer da ineficiência estatal, ora emergindo a noção de ser da própria natureza do Estado nacional a conformação de organizações nos moldes do grupo paulista. Neste segundo aspecto, a expansão contínua do PCC seria uma consequência natural do cenário. Neste sentido, não há necessariamente um ponto pacífico, denotando que as visões dos agentes estatais em relação ao ente que constituem estão em conflito, dizendo o seu cerne respeito a entendimentos distintos sobre a natureza do próprio Estado.

Revisto por Rita Cabral

\section{Referências bibliográficas}

Adorno, Sérgio; Dias, Camila Nunes (2016), "Cronologia dos 'Ataques de 2006' e a nova configuração de poder nas prisões na última década”, Revista Brasileira de Segurança Pública, 10(2), 118-132.

Barbosa, Antônio Rafael (2005), "Prender e dar fuga: biopolítica, sistema penitenciário e tráfico de drogas no Rio de Janeiro". Tese de Doutorado em Antropologia Social, Universidade Federal do Rio de Janeiro, Rio de Janeiro, Brasil.

Biondi, Karina (2014), "Etnografia no movimento: território, hierarquia e lei no PCC". Tese de Doutorado em Antropologia Social, Universidade Federal de São Carlos, São Carlos, Brasil.

Cano, Ignacio; Alvadia, Alberto (coords.) (2008), "Análise dos impactos do PCC em São Paulo em maio de 2006”. Rio de Janeiro/São Paulo: Laboratório de Análise da Violência/Conectas Direitos Humanos.

Das, Vena; Poole, Deborah (2008), "El Estado e sus márgenes: etnografias comparadas", Cuadernos de Antropología Social, 27, 19-52. 
DEPEN - Departamento Penitenciário Nacional (2017), Levantamento nacional de informações penitenciárias. Atualização - Junbo de 2016. Brasília: DEPEN/Ministério da Justiça e Segurança Pública.

Dias, Camila (2007), “Análise da manutenção da identidade evangélica na prisão a partir de uma perspectiva interacionista: focalizando tensões e ambigüidades”, Ciencias Sociales y Religión/Ciências Sociais e Religião, 9(9), 217-240.

Dias, Camila (2011), "Da pulverização ao monopólio da violência: expansão e consolidação do Primeiro Comando da Capital (PCC) no sistema carcerário paulista”. Tese de Doutorado em Sociologia, Universidade de São Paulo, São Paulo, Brasil.

Duarte, Thais Lemos (2019), "Facções criminais e milícias: aproximações e distanciamentos propostos pela literatura”, BIB - Revista Brasileira de Informação Bibliográfica em Ciências Sociais, 90, 1-16. DOI:10.17666/bib9002/2019

Duarte, Thais Lemos; Araújo, Isabela Cristina Alves de (2020), "PCC em pauta: narrativas jornalísticas sobre a expansão do grupo pelo Brasil”, Dilemas - Revista de Estudos de Conflito e Controle Social, 13(2), 505-532.

Feltran, Gabriel de Santis (2010), "Crime e castigo na cidade: os repertórios da justiça e a questão do homicídio nas periferias de São Paulo”, 23(58), 59-73.

Garland, David (2008), A cultura do controle: crime e ordem social na sociedade contemporânea. Rio de Janeiro: Revan. Tradução de André Nascimento.

Lourenço, Luiz Claudio; Dias, Camila Nunes (2015), "Discutindo elementos para a definição e a atuação de coletivos de internos do sistema prisional de São Paulo e da Bahia”. Comunicação apresentada no 39. Encontro Anual da ANPOCS, 26 a 30 de outubro, Caxambu, Brasil.

Manso, Bruno Paes; Dias, Camila (2018), A guerra: a ascensão do PCC e o mundo do crime. São Paulo: Todavia.

Misse, Michel (2006), Crime e violência no Brasil contemporâneo. Rio de Janeiro: Lumen Juris.

Misse, Michel (2010), "Crime, sujeito e sujeição criminal: aspectos de uma contribuição analítica sobre a categoria 'bandido”, Lua Nova: Revista de Cultura e Política, 79, 15-38.

Rafael, Antônio (2001), "As armas do crime: reflexões sobre o tráfico de drogas no Rio de Janeiro”, Civitas - Revista de Ciências Sociais, 1(2), 165-180.

Ramalho, José Ricardo (1983), Mundo do crime: a ordem pelo avesso. Rio de Janeiro: Graal [2. ${ }^{a}$ ed.].

Ramos, Silvia; Musumeci, Leonarda (2005), Elemento suspeito: abordagem policial e discriminação na cidade do Rio de Janeiro. Rio de Janeiro: Civilização Brasileira.

Silvestre, Giane (2016), “'Enxugando iceberg': como as instituições estatais exercem o controle do crime em São Paulo”. Tese de Doutorado em Sociologia, Universidade Federal de São Carlos, São Carlos, Brasil.

Sinhoretto, Jacqueline; Silvestre, Giane; Melo, Felipe Athayde Lins de (2013), “O encarceramento em massa em São Paulo”, Tempo Social, 25(1), 83-106. 
Telles, Vera da Silva (2013), "Prospectando a cidade a partir de suas margens: notas inconclusas sobre uma experiência etnográfica”, Contemporânea, 3(2), 359-373.

Weber, Max (1982), Ensaios de Sociologia. Rio de Janeiro: Guanabara Koogan. Tradução de Waltensir Dutra.

Artigo recebido a 17.08.2018

Aprovado para publicação a 17.01.2020

\section{Thais Lemos Duarte}

Centro de Estudos de Criminalidade e Segurança Pública (CRISP/UFMG) | Programa de

Pós-graduação em Sociologia, Faculdade de Filosofia e Ciências Humanas da Universidade Federal de Minas Gerais (UFMG) I Bolsista de Pós-doutorado Júnior do CNPq

Avenida Presidente Antônio Carlos, n. ${ }^{\circ}$ 6627, Pampulha - Unidade Administrativa III (UFMG),

CEP 31270-901 Belo Horizonte, Minas Gerais, Brasil

Contacto: thais-duarte@hotmail.com

ORCID: https://orcid.org/0000-0002-9149-7387

\section{Vacuum in Power? Reflections on the Spread of the Primeiro Comando da Capital throughout Brazil}

The article aims to discuss the point of view of managers of the federal prison administration on the factors that brought about the spread of the criminal group Primeiro Comando da Capital (PCC) throughout Brazil and the effects of this movement within the prison systems of individual states. Many understand the process as a result of the "absence" of the State in the formulation of public policies and the guarantee of rights. The organization would thus have been the result of power vacuums. On the other hand, there are some points of dissonance in this kind of view, which point out that groups like PCC would have stemmed from actions of the State. The visions are in dispute, corresponding to distinct understandings of the very nature of the State itself.

Keywords: Brazil; organized crime; penal system; power relations; State intervention.

\section{Vide au pouvoir? Réflexions sur la diffusion au Brésil du Primeiro Comando da Capital}

L'article analyse les points de vue des dirigeants de l'administration pénitentiaire fédérale sur les facteurs qui ont causé la diffusion du groupe criminel Primeiro Comando da Capital (PCC) au Brésil et les effets de ce mouvement sur les systèmes pénitentiaires des états de la Fédération du Brésil. Beaucoup considèrent le processus comme le résultat de l'“absence" de l'État dans la formulation de politiques publiques et la garantie des droits. Le groupe serait donc le résultat de vides de pouvoir. Il y a toutefois certains points de dissonance concernant ce type de vision, qui indiquent que les groupes comme le PCC seraient le résultat de l'action même de l'État. En ce sens, deux visions sont en conflit, correspondant à différentes compréhensions de la nature même de l'État. Mots-clés: Brésil; crime organisé; intervention de l'État; relations de pouvoir; système pénitentiaire. 
